\title{
Video Motion Graphic sebagai media promosi aplikasi RushTrail menggunakan Style Isometric
}

\author{
Miftahul Husna Ghawa* \\ *Multimedia and Network Engineering, Batam State Polytechnic \\ ** Informatics Engineering, Batam State Polytechnic
}

\begin{tabular}{|c|c|}
\hline Article Info & ABSTRAK \\
\hline Article history: & Penelitian ini berisi tentang pembuatan video promosi untuk aplikasi \\
\hline Received & RushTrail dari perusahaan RushOwl PTE.LTD yang berjudul Video Motion \\
\hline Received Sept $12^{\mathrm{m}}, 2021$ & Graphic sebagai Media Promosi Aplikasi RushTrail Menggunakan Style \\
\hline Revised Nov $20^{\text {th }}, 2021$ & Isometric. Penggunaan Style Isometric karena dapat memberikan kesan yang \\
\hline Accepted Nov $26^{\text {th }}, 2021$ & indah antara $2 \mathrm{~d}$ dan $3 \mathrm{~d}$ yang membuat design Isometric terasa lebih hidup. \\
\hline Keyword: & $\begin{array}{l}\text { yang terdiri dari } 5 \text { tahap yaitu Development, PreProduction, Production, Post } \\
\text { production, dan Delivery. Analisis yang dilakukan pada penelitian ini adalah }\end{array}$ \\
\hline Motion & menganalisis efektif atau tidaknya video Motion Graphic sebagai media \\
\hline Graphic & $\begin{array}{l}\text { promosi aplikasi Kush I rall bagi pinak KusnowI dengan menggunakan anallsis } \\
\text { EPIC model. Pengujian dilakukan kepada pakar dari Rushowl dan di dapatkan }\end{array}$ \\
\hline Isometric & nilai sebesar 4,47 dengan kriteria sangat setuju dengan arti video ini efektif \\
\hline Video & digunakan oleh pihak rushowl \\
\hline Promosi & \\
\hline
\end{tabular}

\section{Corresponding Author:}

Miftahul Husna Ghawa,

Prodi Multimedia Jaringan, Teknik Informatika,

Politeknik Negeri Batam,

Batam Centre, Jl. Ahmad Yani, Tlk. Tering, Kec. Batam Kota, Kota Batam, Kepulauan Riau 29461

Email: info@polibatam.ac.id

\section{PENGANTAR}

Terdapat banyak sekali cara untuk menyampaikan promosi, salah satunya melalui media video. Media promosi tersebut memiliki banyak tujuan diantaranya mempromosikan produk, baik itu pangan, barang, atau jasa, atau bahkan sebuah aplikasi yang sedang dikembangkan oleh perusahaan. salah satunya yaitu aplikasi RushTrail yang merupakan buatan RushOwl Singapore PTE.LTD

Aplikasi RushTrail merupakan aplikasi baru penyedia jasa transportasi yang memudahkan penggunanya dalam menemukan transportasi untuk perjalanan sehari - hari khususnya bus yang berbasis di singapura. Pihak RushOwl membutuhkan sebuah media untuk mempromosikan aplikasi RushTrail agar masyarakat lebih memahami aplikasi tersebut dan bagaimana cara menggunakan.

Media promosi yang digunakan adalah Motion Graphic dengan menerapkan Style Isometric, Style ini dipilih karena style isometric memiliki bentuk, kesederhanaan, dan kedalaman. style isometric membangkitkan keindahan desain datar tetapi dengan kedalaman dan dimensi tambahan yang membuat setiap elemen lebih menarik secara visual dan lebih mudah dipahami oleh pengguna. [1]. diharapkan dengan video ini akan dapat manfaat yang baik bagi rushowl untuk dapat mempromosikan aplikasi RushTrail.

Penelitian ini bertujuan untuk membuat video promosi yang sesuai dengan permintaan perusahaan. Penelitian ini dibuat dengan metode Villamil-Molina dan menganalisis nya menggunakan parameter EPIC Model untuk menilai keefektifan aplikasi ini yang akan digunakan oleh pihak Rushowl. Target uji pada penelitian ini adalah karyawan dari pihak rushowl karena masukan dari karyawan yang sudah memahami kebutuhan dan tujuan dari pengembangan aplikasi ini diharapkan dapat mewakili kebutuhan kepada target konsumen agar video ini bisa digunakan oleh perusahaan sebagai media promosi. 


\section{METODE PENELITIAN}

\subsection{Tinjauan Pustaka}

Pada pembuatan tugas akhir ini, digunakan beberapa penelitian sebagai referensi dan perbandingan. Penelitian tersebut yaitu : Video Profil Smk Animasi Bina Nusantara Batam Berbasis Motion graphic dan Penerapan Unsur Live Shoot dan Motion graphic studi Kasus video Profil RA Ar-Rasyid Tanjung pinang. Rincian dari penelitian diatas ada didalam tabel 1.

Tabel 1 Tinjauan Pustaka

\begin{tabular}{|c|c|c|c|c|}
\hline Judul & Metode & Penulis (Tahun) & Keterangan & Hasil \\
\hline $\begin{array}{l}\text { Video Profil Smk } \\
\text { Animasi Bina Nusantara } \\
\text { Batam Berbasis Motion } \\
\text { graphic }\end{array}$ & $\begin{array}{l}\text { Villamil- } \\
\text { Molina }\end{array}$ & Utomo (2019) & $\begin{array}{l}\text { Membuat video profil } \\
\text { berbasis Motion } \\
\text { graphic sebagai media } \\
\text { promosi SMK Animasi } \\
\text { Bina Nusantara Batam }\end{array}$ & $\begin{array}{l}\text { Video Profil Smk } \\
\text { Animasi Bina } \\
\text { Nusantara Batam } \\
\text { Berbasis Motion } \\
\text { graphic layak } \\
\text { digunakan } \\
\text { sebagai media } \\
\text { promosi oleh } \\
\text { SMK Animasi } \\
\text { Bina Nusantara } \\
\text { Batam }\end{array}$ \\
\hline $\begin{array}{l}\text { Penerapan Unsur Live } \\
\text { Shoot dan Motion } \\
\text { graphic studi Kasus } \\
\text { video Profil Ra Ar- } \\
\text { Rasyid Tanjung pinang }\end{array}$ & $\begin{array}{l}\text { Luther- } \\
\text { Sutopo }\end{array}$ & Yulandina (2017) & $\begin{array}{l}\text { Membuat video profil } \\
\text { untuk RA Ar-Rasyid } \\
\text { Tanjung Pinang dan } \\
\text { menerapkan unsur Live } \\
\text { Shoot }\end{array}$ & $\begin{array}{l}\text { Teknik live shoot } \\
\text { dan motion } \\
\text { graphic adalah } \\
\text { solusi yang tepat } \\
\text { untuk } \\
\text { penyampaian } \\
\text { informasi pada } \\
\text { video profil yang } \\
\text { memiliki durasi } \\
\text { yang singkat. }\end{array}$ \\
\hline
\end{tabular}

\subsection{Dasar Teori}

\section{A. Media Promosi}

Dalam pembuatan sebuah penelitan diperlukan dasar - dasar teori untuk mendukung dalam pembuatan produk, pada kali ini produk yang dibuat adalah video promosi. Promosi sendiri adalah upaya pemasaran untuk membuat konsumen ingin untuk mencoba yang bersifat media atau non media, dan juga untuk meningkatkan permintaan atau untuk memperbaiki kualitas produk dari konsumen[2].

B. Motion Graphic

Terdapat banyak style yang digunakan dalam membuat sebuah video, salah satunya adalah Motion Graphic. Motion Graphic sendiri adalahsalah satu cabang di ilmu desain grafis, yang didalamnya, elemen elemen desain seperti bentuk, ukuran, tekstur, digerakkan agar tampak hidup. Motion Graphic dengan desain grafis sangatlah berbeda, perbedaannya adalah pada medianya. Desain grafis di aplikasikan pada media cetak atau gambar, sementara Motion Graphic, ditampilkan melalui media audio visual [3].

\section{Isometric}

Pada video promosi ini, diterapkan juga salah satu style dalam desain grafis, style yang digunakan adalah style isometric. Isometric adalah metode menggambar / membuat objek tiga dimensi dalam dua dimensi. Isometric menggabungkan keindahan desain dua dimensi dan tiga dimensi yang membuat setiap elemen lebih menarik secara visual dan lebih mudah dipahami oleh pengguna [1]. style ini di pakai untuk memperindah video promosi yang akan dibuat.

Commented [2]: hasilnya dijelaskan berdasarkan evaluasinya

Commented [3]: hasilnya dijelaskan berdasarkan evaluasinya 
D. EPIC Model

Dalam membuat sebuah penelitian, diperlukan sebuah analisis. Dalam melakukan analisis terdapat banyak sekali metode yang bisa digunakan dan pada penelitian ini analisisnya akan menggunakan metode EPIC Model. EPIC Model merupakan sebuah metode untuk mengukur efektivitas iklan dengan menggunakan pendekatan komunikasi yang dikembangkan oleh AC Nielsen. Terdapat 4 dimensi yang digunakan untuk mengukur efektivitas sebuah iklan yaitu Empathy, Persuaion, Impact, dan Communication. Berikut merupalan penjelasan tentang dimensi-dimensi yang terdapat dalam EPIC model:

1. Empathy

DImensi pertama adalah dimensi Empathy, Dimensi !adalah kemampuan untuk memahami apa yang dirasakan orang lain, melihat dari sudut pandang orang tersebut, dan juga membayangkan diri sendiri berada pada posisi orang tersebut.

\section{Persuasion)}

Dimensi Persuasi merupakan perubahan kepercayaan, sikap, dan keinginan berperilaku yang disebabkan oleh suatu bentuk komunikasi promosi dengan cara memberikan alasan dan prospek baik yang meyakinkannya.

3. Impact)

Dimensi Dampak merupakan hal yang diinginkan dari hasil iklan yaitu kuantitas pengetahuan produk (product knowledge) yang dapat dicapai konsumen melalui tingkat keterlibatan (involvement) konsumen dengan produk atau proses pemilihan.

4. Communication)

Dimensi Komunikasi memberikan informasi tentang kemampuan konsumen dalam mengingat pesan utama yang disampaikan, pemahaman konsumen, serta kekuatan kesan yang ditinggalkan pesan tersebut.

\subsection{Analisis dan Perancangan}

Pembuatan video Motion Graphic sebagai media promosi aplikasi RushTrail ini menggunakan metode Villamil - Molina. Menurut Handoko [6] metode Villamil - Molina memiliki tahapan - tahapan pengembangan multimedia seperti Development, Pre Production, Production, Post production, Delivery.

Dalam proses Development dilakukan penentuan konsep video dan warna dan dalam tahap PreProduction, akan dilakukan penentuan asset, narasi, storyboard, audio, rancangan kuisioner, dan rancangan analisis. Pada tahap Production dilakukan proses tracing, animating, editing, dan rendering. Pada tahap Post production dilakukan proses analisis dan kesimpulan, pada pembuatan video Motion Graphic ini tidak akan ada tahap Delivery karena video ini masih bersifat rahasia dan hanya boleh diketahui oleh pihak perusahaan saja.

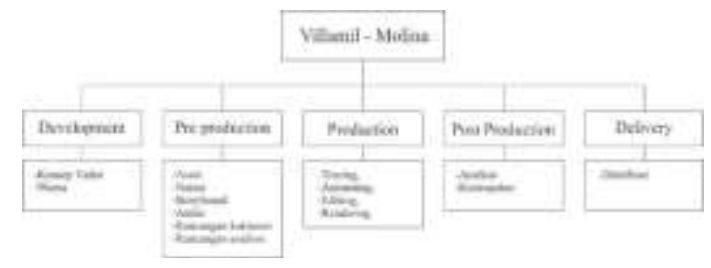

Gambar 1 Alur metode Villamil-Molina

\section{A. Development}

Dalam proses Development pada tugas akhir ini, akan ditentukan konsep video dan juga warna. Konsep video yang akan digunakan adalah video Motion Graphic yang menggunakan Style Isometric yang di gabungkan oleh Typography. Alur cerita dimulai dari penjelasan mengenai problem yang di hadapi sebelum menggunakan aplikasi RushTrail dilanjutkan dengan apa yang di dapatkan jika menggunakan aplikasi 
RushTrail. Video Motion Graphic ini akan di awali dengan ilustrasi isometric dan di ikuti dengan text yang telah disiapkan.

Konsep ini telah dirundingkan bersama CEO dari RushOwl sendiri dan telah disetujui. Durasi yang ditentukan adalah 1 menit. Kemudian terdapat warna standard dari perusahaan seperti pada tabel 2:

\begin{tabular}{|c|c|c|}
\hline $\mathrm{No}_{0}$ & Worno & Keterancan \\
\hline 1 & & $\begin{array}{c}\text { Putih } \\
\text { Kode warna : \#FFFFFF }\end{array}$ \\
\hline 2 & & $\begin{array}{c}\text { Kuning } \\
\text { Kode warna : F4F44E }\end{array}$ \\
\hline 3 & & $\begin{array}{c}\text { Abu - Abu soft } \\
\text { Kode warna : \#3F454D }\end{array}$ \\
\hline 4 & & $\begin{array}{c}\text { Hitam soft } \\
\text { Kode warna : \#232323 }\end{array}$ \\
\hline
\end{tabular}

\section{A. PreProduction}

Pada Proses Pre Production akan ditentukan Asset, Narasi, Storyboard, Audio, dan Analisis dan kuesioner. Asset yang akan digunakan dalam video ini berupa karakter, gambar dan icon dalam bentuk Isometric. Asset yang akan digunakan pada video Motion Graphic telah selesai dibuat dan ditampilkan pada tabel 3 .

Tabel 3 Karakter, gambar, dan icon

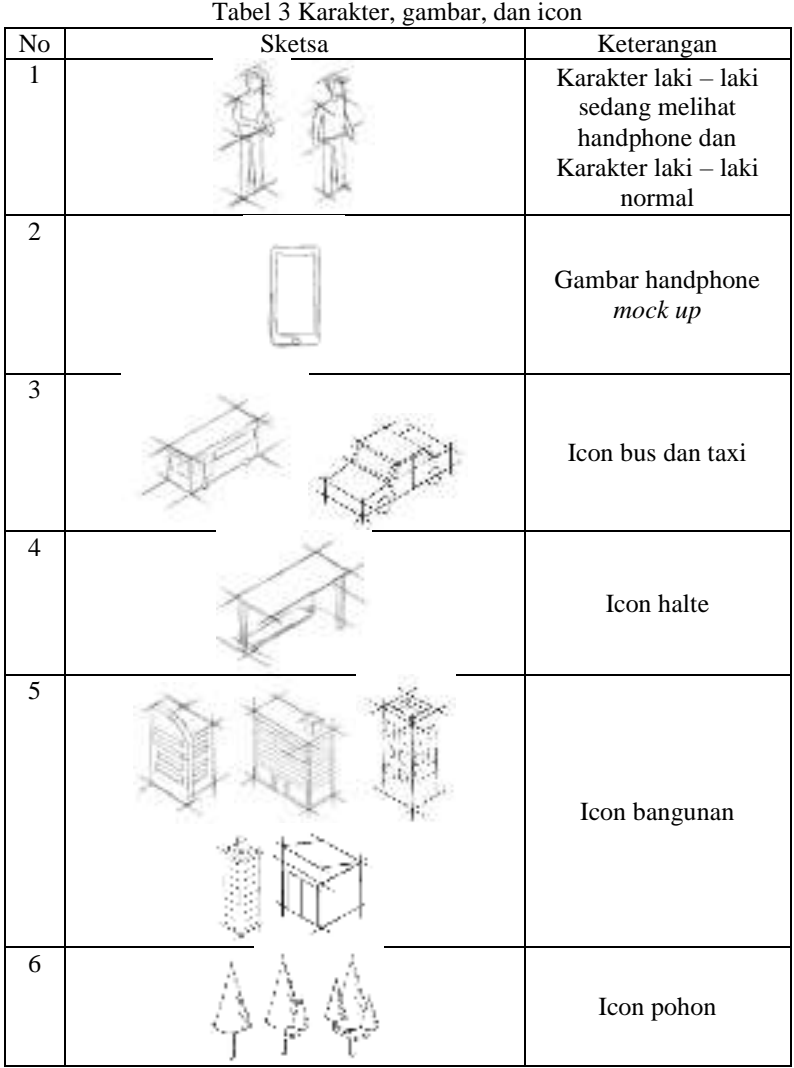

Video Motion Graphic sebagai media promosi aplikasi RushTrail Menggunakan Style Isometric (Miftahul) 
JAMN

\begin{tabular}{|l|l|l|}
\hline 7 & & \\
\hline 8 & & \\
\hline
\end{tabular}

Untuk narasi akan dibentuk menjadi text Typography yang disusun sedemikian rupa yang akan diletakan di dalam video, di video ini tidak terdapat narasi suara/dubbing. Narasi ini merupakan ketentuan dari perusahaan. Narasi disetiap scene dapat dilihat pada tabel 4:

\begin{tabular}{|c|c|c|}
\hline No & Nama & Keterangan \\
\hline 1 & Narasi Scene 1 & $\begin{array}{c}\text { Struggling to find a direct bus to your workplace every } \\
\text { morning? }\end{array}$ \\
\hline 2 & Narasi Scene 2 & Always overspending on taxis to avoid being late? \\
\hline 3 & Narasi Scene 3 & $\begin{array}{l}\text { Introducing the RushTrail app, your trusted buspooling } \\
\text { app }\end{array}$ \\
\hline 4 & Narasi Scene 4 & $\begin{array}{l}\text { Simply suggest your daily route and we will gather similar } \\
\text { comrades to buspool with you! }\end{array}$ \\
\hline 5 & Narasi Scene 5 & $\begin{array}{l}\text { You can also discover different shuttle bus routes in } \\
\text { various Singapore landmarks } \\
\text { *Be updated about the whereabouts and the Estimated } \\
\text { Time Arrival of your bus! }\end{array}$ \\
\hline 6 & Narasi Scene 6 & Get more discounts with our weekly and monthly passes! \\
\hline 7 & Narasi Scene 7 & $\begin{array}{l}\text { Wait no more! Download the RushTrail app today and } \\
\text { buspool with us. Your Shuttle Bus,Reimagined }\end{array}$ \\
\hline
\end{tabular}

Motion Graphic ini memiliki storyboard sebagai acuan dalam pembuatan video ini. Pada storyboard, konsep video akan di pecah hingga beberapa scene agar mudah dalam membuat produk video Motion Graphic ini. Pada storyboard juga diatur untuk waktu per tiap scene nya. Contoh storyboard untuk scene 1 untuk video Motion Graphic ini dapat dilihat dalam tabel 5:

\begin{tabular}{|c|c|l|}
\multicolumn{3}{|c|}{ Tabel 5 Contoh bentuk storyboard } \\
\hline No & \multicolumn{1}{|c|}{ Scene } & \multicolumn{1}{|c|}{ Keterangan } \\
\hline \multirow{2}{*}{1} & Scene 1 & \multicolumn{1}{|c|}{ Time : 00:00:01 - 00:00:09 } \\
\cline { 2 - 3 } & & $\begin{array}{l}\text { Narasi: } \\
\text { Struggling to find a direct bus to your workplace every } \\
\text { morning? } \\
\text { Audio: } \\
\text { Background Music } \\
\text { Ket : detik 1 - 3 muncul bangunan dan pohon,detik 4 } \\
\text { muncul tulisan, detik 5 muncul bus dan jalan }\end{array}$ \\
\hline
\end{tabular}

Dalam pembuatan video ini terdapat audio yang berupa background music dan tidak menggunakan dubbing karena sesuai dengan permintaan perusahaan. Audio yang digunakan adalah Corporate Background Music dari No Copyright Music jadi musik ini bebas digunakan tanpa takut terkena copyright.

Lalu ada rancangan kusioner yang akan diberikan kepada pakar .Kuisioner yang diberikan adalah kuisioner keefektifan produk dengan cara menyusun pernyataan yang berkaitan dengan parameter EPIC Model dan akan di pakai untuk pengujian yang berbentuk seperti pada table 6 :

\section{Tabel 6 Rancangan Kuisioner Pernyataan EPIC Model}

\begin{tabular}{|c|c|c|}
\hline Parameter & Pernyataan & No \\
\hline
\end{tabular}

Video Motion Graphic sebagai media promosi aplikasi RushTrail Menggunakan Style Isometric (Miftahul) 


\begin{tabular}{|c|l|c|}
\hline \multirow{2}{*}{ Dimensi Empati } & (X1) Video Motion Graphic ini bagus untuk dilihat & 1 \\
\cline { 2 - 3 } Dimensi Persuasi & $\begin{array}{l}\text { (X3) Video Motion Graphic ini mudah diingat } \\
\text { tentang aplikasi RushTrail }\end{array}$ & 2 \\
\cline { 2 - 3 } & $\begin{array}{l}\text { (X4) Video Motion Graphic ini membuat saya yakin terhadap } \\
\text { aplikasi RushTrail }\end{array}$ & 4 \\
\hline \multirow{5}{*}{ Dimensi Dampak } & $\begin{array}{l}\text { (X5) Video Motion Graphic ini membuat saya mengerti cara } \\
\text { kerja aplikasi RushTrail }\end{array}$ & 5 \\
\cline { 2 - 3 } & $\begin{array}{l}\text { (X6) Video Motion Graphic ini membuat saya ingin } \\
\text { menggunakan aplikasi RushTrail }\end{array}$ & 6 \\
\hline Dimensi & $(\mathrm{X} 7)$ Video Motion Graphic ini sudah jelas & 7 \\
\cline { 2 - 3 } Komunikasi & $(\mathrm{X} 8)$ Video Motion Graphic ini mudah dimengerti & 8 \\
\hline
\end{tabular}

Metode yang akan digunakan untuk menganalisa produk ini adalah Metode Kuantittif. dan untuk pengambilan sampel nya akan menggunakan Teknik Sampling jenuh. Teknik Sampling Jenuh digunakan bila jumlah populasi kurang dari 30 orang dan seluruh populasi akan dijadikan sampel [7]. Sampel yang diambil untuk pengujian adalah pakar yang merupakan staff rushowl yang berjumlah 9 orang.

Pengujian dilakukan dalam bentuk pemberian kuisioner dengan menggunakan parameter EPIC Model. Untuk bagian analisis, data dihitung dengan menggunakan rumus skor rata-rata yang dimana setiap jawaban responden diberikan suatu nilai. Penghitungan skor akan dilakukan dengan cara menjumlahkan seluruh hasil data lalu dikalikan dengan nilai masing-masing dan dibagi dengan jumlah total data [8].

$$
\mathrm{X}=\frac{\sum f i \cdot w i}{\sum f i} \quad \begin{array}{ll} 
\\
\\
\mathrm{X} & =\text { Rata }- \text { rata } \\
\mathrm{Fi} & =\text { Frekuensi } \\
\mathrm{Wi} & =\text { bobot nilai }
\end{array}
$$

Gambar 1 Rumus Skor rata- rata [8]

Langkah selanjutnya adalah mencocokan nilai yang telah dihitung kedalam 5 kategori yang dibuat menggunakan rentang skala, Rentang skala dibuat dengan menggunakan skala antara 1 sampai 5 yang memiliki kategori dari sangat tidak setuju ke posisi yang sangat setuju. Didapatkan hasil rentang skala sebesar 0,8 dari perhitungan (bobot terbesar - bobot terkecil) / banyak kategori bobot [8]. Hasil tersebut digunakan dalam ke dalam rentang skala keputusan sebagai bahan pengambilan keputusan dari hasil analisis EPIC Model pada tabel 7:

Tabel 7 Rentang Skala

\begin{tabular}{|c|c|}
\hline Kriteria & Rentang skala \\
\hline Sangat Tidak Setuju (STS) & $1,00-1,80$ \\
\hline Tidak Setuju (TS) & $1,81-2,60$ \\
\hline Ragu - Ragu (RR) & $2,61-3,40$ \\
\hline Setuju (S) & $3,41-4,20$ \\
\hline Sangat Setuju (SS) & $4,21-5,00$ \\
\hline
\end{tabular}


Langkah terakhir adalah menentukan nilai EPIC Rate lalu di cocokan ke rentang skala untuk mengetahui nilai kriteria dari setiap parameter EPIC model yang akan menentukan efektif tidaknya produk Motion Graphic ini [5]. EPIC Rate bisa tentukan dengan rumus yang dapat dilihat pada gambar 2:

$$
\text { EPIC Rate }=\frac{\text { Xempati }+X \text { persuasi }+X \text { dampak }+X k o m u n i k a s i}{N}
$$

Gambar 2 Rumus EPIC Rate [8]

Keterangan :

Xempati $\quad=$ rata - rata nilai parameter empati

Xpersuasi $\quad=$ rata - rata nilai parameter persuasi

Xdampak = rata - rata nilai parameter dampak

Xkomunikasi $=$ rata - rata nilai parameter komunikasi

\section{HASIL DAN ANALISA}

Dalam bagian ini akan dijelaskan tentang Hasil dan Analisa, Pada bagian hasil merupakan proses Production yang akan meliputi tentang tracing, animating, editing, dan rendering .

3.1. Hasil

A. Tracing

Setelah membuat sketch seperti di atas, selanjutnya akan di tracing hinga menjadi sebuah icon, Grid akan dibuat terlebih dahulu sebagai acuan dalam proses tracing. Proses ini dilakukan untuk semua sketsa yang telah dibuat, dan akan menjadi hasil akhir, proses tracing bisa dilihat pada gambar 3 .

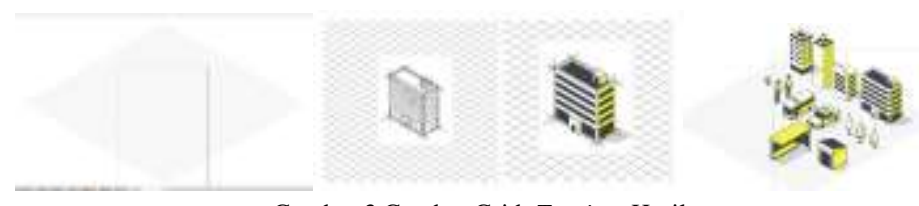

B. Animating

Gambar 3 Gambar Grid, Tracing, Hasil

Setelah Proses Tracing semua hasil asset dimasukan ke dalam Adobe After Effect untuk dilakukan proses animating. Proses animating memberikan animasi yang sesuai kepada asset di dalam tiap - tiap scene nya digabungkan dengan text dari narasi dari tiap scene dan disesuaikan dengan storyboard. proses animating dilakukan pada tiap scene bisa dilihat pada gambar 4 :

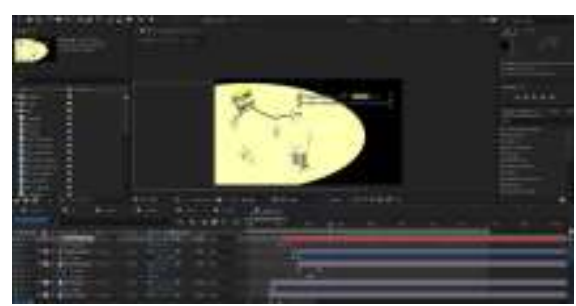

Gambar 4 Proses Animating 
C. Editing

Setelah proses animating setiap scene selesai, langkah selanjutnya ada proses editing menggunakan Adobe Premier untuk menggabungkan semua scene dan juga menambah kan audio. Proses editing bisa dilihat pada gambar 5 .

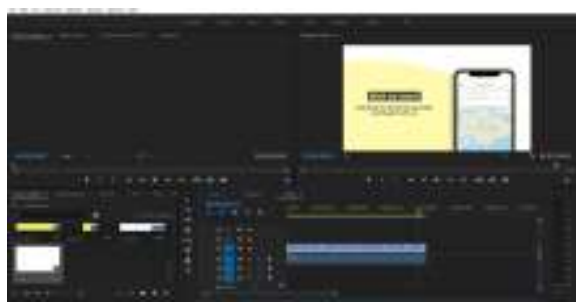

Gambar 5 Proses Editing

\section{Rendering}

Setelah proses editing selesai, video Motion Graphic ini kemudian di render agar menjadi hasil akhir berupa file video sebelum di distribusikan, proses rendering bisa dilihat pada gambar 6 .

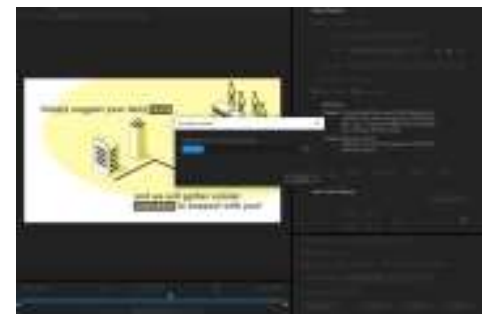

Gambar 6 Proses Rendering

\subsection{Analisa}

Analisis dilakukan dengan cara menyebar kuesioner kepada seluruh staf perusahaan yang berjumlah 9 orang, data kuesioner yang didapatkan ada pada tabel 8 .

\begin{tabular}{|c|c|c|c|c|c|c|}
\hline Parameter & Pernyataan & SS & $S$ & RR & TS & STS \\
\hline \multirow{2}{*}{$\begin{array}{c}\text { Dimensi } \\
\text { Empati }\end{array}$} & (X1) & 5 & 3 & 1 & 0 & 0 \\
\hline & (X2) & 4 & 3 & 1 & 1 & 0 \\
\hline \multirow{2}{*}{$\begin{array}{l}\text { Dimensi } \\
\text { Persuasi } \\
\end{array}$} & (X3) & 6 & 2 & 0 & 1 & 0 \\
\hline & (X4) & 6 & 1 & 2 & 0 & 0 \\
\hline \multirow{2}{*}{$\begin{array}{l}\text { Dimensi } \\
\text { Dampak }\end{array}$} & (X5) & 4 & 5 & 0 & 0 & 0 \\
\hline & (X6) & 5 & 4 & 0 & 0 & 0 \\
\hline \multirow{2}{*}{$\begin{array}{c}\text { Dimensi } \\
\text { Komunikasi }\end{array}$} & (X7) & 8 & 0 & 1 & 0 & 0 \\
\hline & (X8) & 6 & 2 & 1 & 0 & 0 \\
\hline
\end{tabular}

Setelah di dapat data di atas, kemudian dilakukan penghitungan dengan Rumus skor rata- rata untuk mencari rata-rata per parameter dan menggunakan rumus EPIC rate untuk mencari nilai EPIC rata - rata , contoh penghitungan dapat dilihat pada gambar 7. 


$$
\begin{aligned}
& \text { Nilai Dimensi Empati }=\frac{\text { Nilai X1 + Nilai X2 }}{2} \\
& \text { Nilai X1 }=\frac{(5 \times 5)+(3 \times 4)+(1 \times 3)}{9}=4,44 \\
& \text { Nilai } X 2=\frac{(4 \times 5)+(3 \times 4)+(1 \times 3)+(1 \times 2)}{9}=4,11 \\
& \text { Nilai Dimensi Empati - } \frac{4,44+4,11}{2}=4,27
\end{aligned}
$$

Gambar 7 Penghitungan data kuisioner Dimensi Empati

Lalu dilanjutkan untuk menghitung semua nilai dimensi, hasil penghitungan dan kriteria setiap dimensi dapat dilihat pada tabel 9 .

Tabel 9 Hasil penghitungan data kuisioner

\begin{tabular}{|c|c|c|}
\hline Parameter & Nilai & Kriteria \\
\hline Dimensi Empati & 4,27 & Sangat Setuju \\
\hline Dimensi Persuasi & 4,44 & Sangat Setuju \\
\hline Dimensi Dampak & 4,57 & Sangat Setuju \\
\hline Dimensi Komunikasi & 4,66 & Sangat Setuju \\
\hline
\end{tabular}

Setelah itu di masukan kedalam rumus EPIC Rate untuk mengetahui hasil akhir, hasil penghitungan lebih lengkap dapat dilihat pada gambar 8 .

$$
\begin{aligned}
& \text { Nilai EPIC Rate }=\frac{4,27+4,44+4,57+4,66}{4} \\
& \text { Nilai EPIC Rate }=4,47 \\
& \quad \text { Gambar } 8 \text { Penghitungan EPIC rate }
\end{aligned}
$$

Nilai EPIC Rate adalah 4,47 dengan kriteria Sangat Setuju.

\section{KESIMPULAN}

Berdasarkan hasil penelitian yang telah dilakukan pada jurnal ini, maka dapat diambil kesimpulan yang berarti Video Motion Graphic sebagai media promosi aplikasi RushTrail Menggunakan Style Isometric EFEKTIF digunakan oleh pihak perusahaan (Rushowl) sebagaimana mestinya untuk keperluan promosi.

Hasil ini didapatkan dari analisis dan penghitungan yang dilakukan pada proses post production. Analisa dilakukan dengan cara membagikan kuisioner yang berisi pertanyaan yang terbagi dalam 4 dimensi, setiap dimensi memiliki 2 pertanyaan. Setelah data kuisioner didapatkan, maka dilanjutkan dengan proses penghitungan, proses penghitungan dilakukan dengan cara mencari hasil rata - rata di setiap dimensi lalu memasukan hasilnya ke rusus EPIC rate. Hasil EPIC Rate yang didapatkan adalah 4,47 dengan kriteria sangat setuju, yang artinya responden sangat setuju dengan pernyataan kuesioner tentang keefektifan video Motion Graphic ini. 


\section{DAFTAR PUSTAKA}

[1] Cousins, Carrie. 2019. Isometric Design \& Illustration: An Eye-Catching Trend, https://designshack.net/articles/trends/isometric-design-illustration/. [Diakses pada 20 Juli 2020]

[2] Sustina, 2003. Perilaku Konsumen Dan Komunikasi Pemasaran. PT.Remaja Rosdakarya, Bandung

[3] Umam, Nuga Choiril, 2016, Perancangan Motion Graphic Pengenalan Batik Gemawang Khas Kabupaten Semarang, Jurnal Tugas Akhir, Institut Seni Indonesia Yogyakarta.

[4] Velarde, Orana. 2018. Understanding illustration. https://www.freepik.com/blog/understanding-Isometricillustration/. [Diakses pada 17 Juli 2020]

[5] Durianto, Darmadi. 2003. Invasi Pasar Dengan Iklan Yang Efektf. Erlangga, Jakarta

[6] Santoso, Handoko. 2017. Tinjauan Metode Pengembangan Perangkat Lunak Multimedia Yang Sesuai Untuk Mahasiswa Tugas Akhir. https://docplayer.info/50879193-Tinjauan-metode-pengembangan-perangkat-lunakmultimedia-yang-sesuai-untuk-mahasiswa-tugas-akhir.html. [Diakses pada 20 October 2019]

[7] Sugiyono. 2014. Metode Penelitian Pendidikan Pendekatan Kuantitatif, Kualitatif, dan R\&D. Alfabeta. Bandung

[8] Kembaren, Teguh. 2018. IMPLEMENTASI MOTION GRAPHIC PADA VIDEO PROMOSI CGV E-CARD MEMBER (Studi Kasus: CGV CINEMAS). Tugas Akhir, Politeknik Negeri Batam 